\title{
Bronchiolitis obliterans organizing pneumonia secondary to amiodarone: a rare aetiology
}

\author{
J.M. Valle*, D. Alvarez*, J. Antúnez**, L. Valdés*
}

\begin{abstract}
Bronchiolitis obliterans organizing pneumonia secondary to amiodarone: a rare aetiology. J.M. Valle, D. Alvarez, J. Antúnez, L. Valdés. CERS Journals Ltd 1995.

ABSTRACT: Bronchiolitis obliterans organizing pneumonia (BOOP) is a clinicopathological entity with well-defined diagnostic criteria, the aetiology of which is generally unknown. Among the adverse pulmonary effects of the drug amiodarone, BOOP is the least commonly reported in the literature. In this article we describe a case of amiodarone-induced BOOP.
\end{abstract}

Eur Respir J., 1995, 8, 470-471.

Bronchiolitis obliterans organizing pneumonia (BOOP) is a clinicopathological entity characterized by: 1) a pneumonia-like clinical presentation and a history of rapidly progressive dyspnoea; 2) visualization of patchy infiltrates on chest radiographs and/or computed tomography (CT); and 3) histopathological evidence of intraluminal organization, especially in alveolar ducts [1]. In most cases the aetiology remains unknown, although it has been associated with specific diseases and causes including bacterial or viral infections, diseases of the connective tissue, radiation therapy, myelodysplastic syndrome, cocaine abuse, human immunodeficiency virus (HIV) infection, gastrointestinal disorders, and various pharmaceutical drugs [2]. One of the drugs reported to cause BOOP is amiodarone. In this article, we describe the case of a patient recently treated for BOOP secondary to amiodarone therapy.

\section{Case report}

A 61 year old housewife was admitted to our hospital in November 1993 following 15 days of unproductive coughing, left hemithoracic pain reminiscent of pleuritis, moderate fever $\left(38^{\circ} \mathrm{C}\right)$, asthenia and anorexia. She did not smoke or drink alcohol, but for the last 8 yrs had taken $200 \mathrm{mg}$ of amiodarone (Trangorex $\AA$ ) five days a week to control cardiac arrhythmia (a cumulative total dose of $370 \mathrm{~g}$ ).

Upon physical examination, the only relevant finding was crepitation in the inferior left lung. Blood counts indicated slight leucocytosis $\left(11.6 \times 10^{9}\right.$ cells $\left.\cdot l^{-1}\right), 84 \%$ neutrophils, and a erythrocyte sedimentation rate of $124 \mathrm{ml}$. Biochemical variables were normal. A chest radiograph revealed an alveolar opacity in the left inferior lobe (fig. 1). Arterial blood gas measurements showed moderate hypoxaemia, arterial oxygen tension $\left(\mathrm{PaO}_{2}\right) 8.4$

\author{
*Sección de Neumología, Hospital de Conxo, \\ **Servicio de Anatomía Patológica, Hospi- \\ tal General de Galicia, Santiago de Com- \\ postela, Spain. \\ Correspondence: J.M. Valle, Sección de \\ Neumología, Hospital de Conxo, Rúa Dr. \\ Ramón Baltar s/n, 15706 Santiago de \\ Compostela, La Coruña, Spain \\ Keywords: Amiodarone, bronchiolitis ob- \\ literans organizing pneumonia \\ Received: 30 October 1994 \\ Accepted after revision November 61994
}

$\mathrm{kPa}(63 \mathrm{mmHg})$ with normocapnia, arterial carbon dioxide tension $\left(\mathrm{PaCO}_{2}\right) 5.1 \mathrm{kPa}(38 \mathrm{mmHg})$.

Pneumonia was diagnosed, and erythromycin therapy initiated ( $1 \mathrm{~g}$ q.i.d.). After 5 days the symptoms persisted, and crepitation had also begun in the inferior right lung, which was also shown to have an infiltration on chest radiography (fig. 2). CT confirmed the bilateral presence of basal pulmonary infiltrates, and pulmonary function tests showed reduced diffusion (single-breath diffusing capacity for carbon monoxide (DsbCO) $47 \%$ predicted, diffusion/alveolar volume (D/VA) 60\%). The results of serological tests for connective tissue disease, atypical pneumonias and viral infections were negative. Bronchoalveolar lavage fluid had a normal cell count $\left(12 \times 10^{9}\right.$ cells $\cdot l^{-1)}$ but a high lymphocyte count $(30 \%)$. Transbronchial biopsy allowed no diagnosis. Lung biopsy samples obtained by thoracotomy exhibited granulation tissue of oedematous aspect occluding the bronchioles and alveolar ducts, with associated areas of fibrous

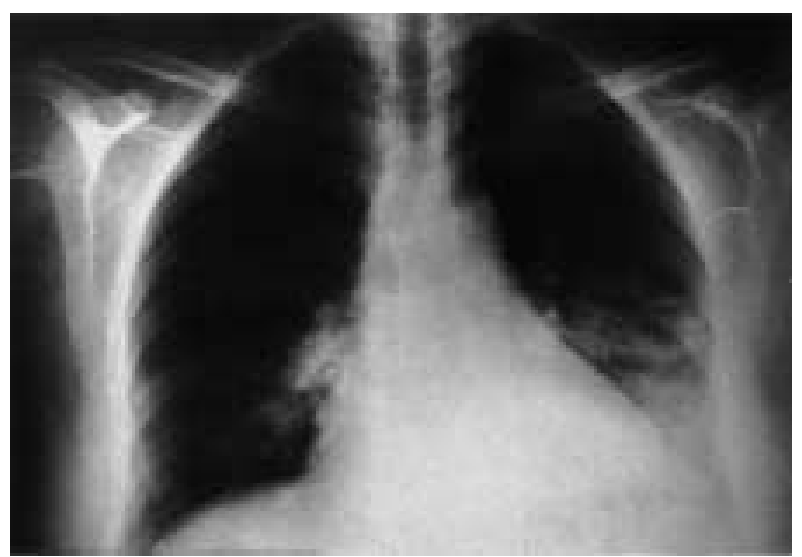

Fig. 1 - Posteroanterior chest radiograph, showing infiltration of the inferior lobe of the left lung. 


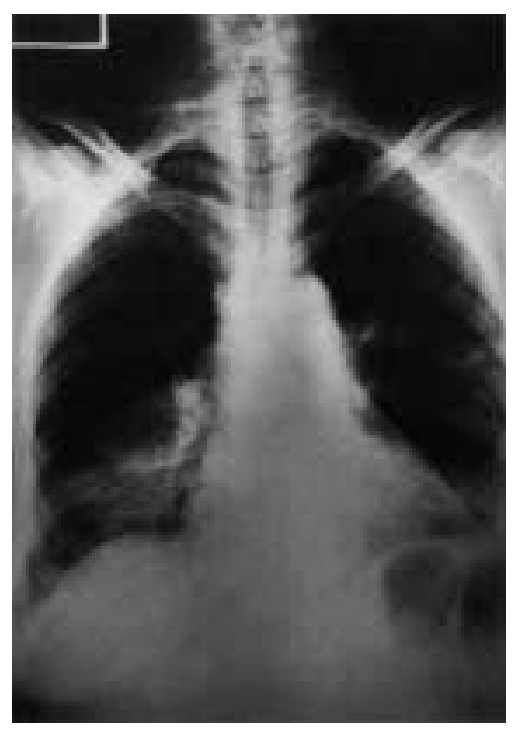

Fig. 2. - Posteroanterior chest radiograph, showing a new infiltrate in the right lung.

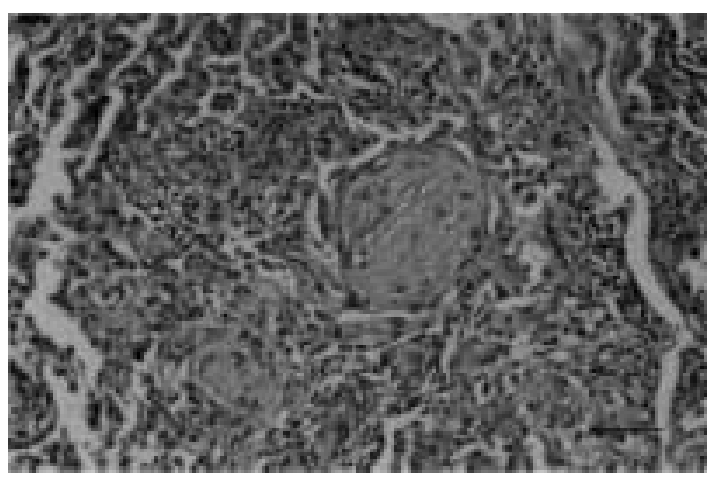

Fig. 3. - Oedematous masses of granulation tissue obstructing the airways. (Haematoxylin and eosin stain; magnification $\times 200$; internal bar $=100 \mu \mathrm{m})$.

scarring and fibrous thickening of the intra-alveolar walls (fig 3). Foci foamy alveolar cells were also observed.

The patient was taken off amiodarone and prednisone was initiated (1 mg.kg-1 daily) in December 1993, with satisfactory clinical results. Two months later, the pulmonary infiltrates had disappeared and the results of pulmonary function tests were normal.

\section{Discussion}

A general syndrome of rapidly progressive dyspnoea with moderate fever and the appearance of patchy infiltrates on chest radiographs and CT scans, together with biopsy samples showing the obstruction of terminal bronchioles and alveolar ducts by granulation tissue, are the findings considered by EPLER et al. [1] to be characteristic of BOOP. BOOP has been associated with a variety of pathologies and specific causes, including connective tissue diseases, gastrointestinal infections and reactions to drugs [2]. Our patient had taken a cumulative total dose of $370 \mathrm{~g}$ of amiodarone over the previous $8 \mathrm{yrs}$, and the results of the tests carried out appear to be sufficient grounds for ruling out other known causes of BOOP.

Amiodarone is an iodine derivative of benzofuran, which has proved effective for treatment of certain arrhythmias. It can, however, exhibit several undesirable properties, the most serious being its pulmonary toxicity, which affects $5-7 \%$ of patients to whom it is administered, and can limit its clinical efficacy [3]. The specific pulmonary effects of this toxicity vary, but include: 1) chronic interstitial pneumonitis with fibrosis; 2) diffuse alveolar damage; and 3) BOOP [4]. The risk of such adverse effects depends both on the daily dose of amiodarone and the duration of treatment, i.e. it appears that the cumulative total dose is more relevant than the daily dosage level [3].

There is no pathognomonic finding identifying amiodarone lung. In all its clinical forms, foamy alveolar macrophages typically appear in biopsy tissue and bronchoalveolar lavage fluid, but they are also found in most amiodarone-treated patients showing no signs of adverse pulmonary effects. A diagnosis of BOOP secondary to amiodarone must, therefore, be based on confirmation of BOOP, prior ingestion of a large enough cumulative dose of amiodarone to cause toxic effects, and sufficient evidence to rule out other possible causes of BOOP. These were the criteria used by CAMUs et al. [5] and Costabel et al. [6] to diagnose BOOP secondary to amiodarone in what, as far as we know, have been the only two cases reported previously. However, several reports of amiodarone pneumonitis have mentioned bronchiolitis or alveolar fibrosis, or both, in conjunction with interstitial pneumonitis with foamy alveolar macrophages, without a diagnosis of BOOP having been made [7]. In view of the above criteria, we believe our patient had BOOP secondary to amiodarone.

Since amiodarone has a long half-life and accumulates in target tissues, such as the lung [8], its withdrawal generally needs to be accompanied by administration of corticoids for speedy resolution of symptoms.

In conclusion, past ingestion of drugs should be carefully investigated in any case of BOOP. In particular, amiodarone should be borne in mind as a possible cause.

\section{References}

1. Epler GR, Colby TV, McLoud TC, Carrington CB, Gaensler EA. Bronchiolitis obliterans organizing pneumonia. N Engl J Med 1985; 312: 152-158.

2. Cordier JF. Cryptogenic organizing pneumonitis: bronchiolitis obliterans organizing pneumonia. Clin Chest Med 1993; 14: 677-692.

3. Martin WJ II, Rosenow EC III. Amiodarone pulmonary toxicity: recognition and pathogenesis. Part I. Chest 1988; 93: 1067-1075.

4. Edward C, Rosenow EC III, Myers JL, Swensen SJ, Pisani RJ. Drug-induced pulmonary disease: an update. Chest 1992; 102: 239-250.

5. Camus P, Lombard JN, Perrichon M, et al. Bronchiolitis obliterans organizing pneumonia in patients taking acebutolol or amiodarone. Thorax 1989; 44: 711-715.

6. Costabel U, Teschler H, Schoenfeld B, et al. BOOP in Europe. Chest 1992; 102: 14S-20S.

7. Myers JL, Kennedy JI, Plumb VJ. Amiodarone lung. Hum Pathol 1987; 18: 349-354.

8. Darmanata JI, Van zandwijk N, Düren DR, et al. Amiodarone pneumonitis: three further cases with review of published reports. Thorax 1984; 39: 56-64. 